\title{
Financial Market Evaluative Inefficiencies and Companies Sub-Optimal Investment Choices: How to Get Out of the Shortermist Impasse?
}

\author{
Bruna Ecchia ${ }^{1}$ \\ ${ }^{1}$ Department of Economics and Statistics, University of Naples Federico II, Italy \\ Correspondence: Bruna Ecchia, Department of Economics and Statistics, University of Naples Federico II , Via \\ Cinthia 26 Monte S. Angelo, 80126 Napoli, Italy. E-mail: bruna.ecchia@unina.it
}

Received: March 29, 2017

Accepted: April 22, 2017

Online Published: April 25, 2017

doi:10.5539/ijef.v9n5p143

URL: https://doi.org/10.5539/ijef.v9n5p143

\begin{abstract}
This paper examines, in an innovative way as compared to the literature on the subject, "whether, how and under what conditions" certain technical devices, such as so-called "loyalty bonuses," devised to increase the holding period of shares, can effectively reach their goal of countering the short-termist tendency involved in company investment decisions. This trend is an expression of compliance toward the current short-termism of the financial market as evidenced by the enormous shortening of the average share-holding period. This is not a recent phenomenon but it becomes more marked in times of crisis. Thus many projects, although functional to a company's competitiveness, are rejected simply because of their deferred profitability and therefore incompatibility with the short market horizon, more focused on results emerging from quarterly reports than on a company's long-term choices for business development. If the market is unable to immediately and adequately incorporate into prices the benefits from deferred returns, shareholders can equally obtain them if they remain durably connected with the company, but this choice must be encouraged by appropriate incentives. The loyalty bonus may be useful for this purpose and for long-term company interests, because it contributes to a better alignment of shareholders' expectations with a more long-term vision in investment strategy. However the bonus, rather than involving the minority shareholders in the enterprise's "mission," often degenerates into a Control Enhancing Mechanism, though with unusual effects, among which a situation of "captivity" for all shareholders, even and especially the majority shareholders. In any case the utility of the bonus can occur, especially in less efficient markets. In a fully efficient market it could be harmful.
\end{abstract}

Keywords: agency problem, control enhancing mechanism, corporate ownership, long-termism, loyalty bonus, market inefficiency, project selection

\section{Introduction}

The purpose of this paper is to verify whether a purely technical expedient such as the loyalty bonus on shares held continuously by the same shareholder for a predetermined minimum period can produce a renewed balance in the process of selecting business projects, currently positioned excessively on the prospect of a short payback period. At the root of this distorted situation I suppose there is mostly a repercussion on the investors' sensitivity to risk over the increased uncertainty of macroeconomic scenarios, in close interaction with financial ones. This uncertainty, which is functional only to financial speculation, generates a widespread shift toward short-term investment preferences in most small investors because of their inadequate interpretation of the more complex situation, which causes them to see in the long term in itself an independent source of unquantifiable risk. This heightened uncertainty of scenarios combines with traditional elements of uncertainty that are connected to the agency problem.

In this situation the investment horizon of shareholders tends to shrink a great deal, and the criteria for evaluating the advantages of staying with one company or switching to another are today founded largely on comparing their respective quarterly reports rather than on the company's prospects of maintaining competitive conditions. In this way, the shortening of the horizon of a growing number of shareholders (minority shareholders who clearly are the ones that bolster the "floating") exerts similar shortening pressure of the time horizon of the investment choices of those companies that fear the consequences of the decline of the courses (more expensive 
fund raising, greater exposure to the risk of hostile takeovers), due to the exit of disappointed shareholders. Paradoxically, the fear generated by the uncertainty of the scenarios can also compress innovative long-term investments that are often those best able to sustain a company's competitiveness in such scenarios but whose deferred income cannot contribute to supporting its short-term income.

Thus companies are in the unhappy situation of making a choice among the following alternatives:

A. A physiological process of selecting projects whose long-term part is quantitatively and qualitatively compatible with the objective of a sustainable development of the company over time but not with investors' expectations, causing a reduction in the market price of shares.

B. A project selection process that is closer to the short-term perspective of the market but not to the guidelines of a company's sustainable development, thereby reducing its competitiveness.

C. Delisting as a way to avoid any market disadvantage. In this case, however, it is the fund raising of the enterprise that may be penalized.

Is there an alternative to these three options, all of which are penalizing? It doesn't seem so. Instead the following compromise has seemed rational to many operators: opting for choice A but with some form of compensation to shareholders to induce them to remain in the company. The compensation lies in an award dependent on shareholder loyalty attested by a prior and uninterrupted continuity of the share in the hands of a single shareholder, at least for a defined period of time. This condition of a prior "loyalty period" is absolutely crucial in this research. Other crucial questions arise as to the subsequent maintenance of this loyalty, with different solutions from one type of bonus to another. The target of these bonuses is generally the group of small, usually "silent" and fairly stable (especially in the past, much less nowadays) shareholders, along with some type of institutional investors managing "patient" capital. Instead, it is very unlikely that such bonuses can attract the interest of speculators.

Obviously, the success of any type of bonus loyalty is largely influenced by the way it is structured, which in turn depends on the particular objectives that the company (actually the agent) pursues. In this regard the real intention of the agent may be not to hold onto the shareholders to avoid the negative consequences of excessive "exits" but rather to obtain an albeit masked control enhancing mechanism. Therefore numerous questions arise about the ostensive purposes and the actual ones of the bonus and its connection to the interests of a portion of the shareholders, rather than to those of all the shareholders. The range of these issues is therefore very broad and can be summarized in the following paragraphs.

What are the bonus structures most likely to achieve the purpose of holding onto shareholders? Does the bonus simply aim at inducing investors to keep their shares for a longer time? Is the longer holding period in itself sufficient to arouse in shareholders any real interest in innovative investments with deferred returns? Or to achieve this do we rather need a more complex turnaround in investor preferences, in particular is it necessary to shift from a psychology of occasional investors to that of a member of a community that shares in the general long-term project that is the company itself? And so will investors appreciate the individual projects, each with its own timing of returns whose function is to contribute to this single general project? And are the current bonus types consistent with this aim of greater convergence of all or most of the shareholders onto this overall project or do some or all of the current bonuses function as Control Enhancing Mechanisms that worsen the agency problem and deepen the rift between majority and minority shareholders? And does this degeneration of the purposes of the bonus necessarily jeopardize the aim of halting the decline of long-termism in the choices of company projects?

This research will try to find convincing answers to these questions by analyzing the very logical basis underlying the loyalty bonus and also, through a comparative analysis of the positive and negative aspects of different types of bonuses. The focus will be on both economic type bonuses, in particular the recent Bolton and Samama bonus model that has sparked new discussions and expectations, and on the classic French model, recently revised, based on an increased vote. However, other possible types of bonus will also be considered and their ability to play an alternative role will be tested.

The analysis that follows is based on a qualitative method and is structured according to the following set of arguments.

Section two will deal with phenomena that are at the root of growing market short-termism and related influences on the selection of company investments. In section three our analysis will focus on empirical means, and specifically on loyalty bonuses, which are designed to counter short-termism. Subsequently, in section four, we will analyze the central point: whether some type of bonus can reduce short-termism as well as the agency 
problem as joint conditions for promoting a participative company spirit, in line with Hirschman's ideas. As this section will show, although the purpose of a greater long-termism in governance can be achieved with at least one bonus, the French type, and with it an increased long-termism in the selection of investment projects, the way to achieve these goals is often overturned with respect to what is necessary for achieving the initial declared intent of the bonus, which is to promote a more massive involvement of shareholders in the company's mission. Moreover, as becomes clear in the conclusions, the bonus can mitigate the effects of irrational market behavior, while it would be useless, if not harmful, in a very efficient market.

\section{At the Roots of Increased Short-Termism in the Selection of Company Projects: Emerging Issues and Responses in the Literature and in Operational Practice}

The statistics about on the average holding period in the major stock markets are all the more significant. If we take the NYSE (New York Stock Exchange Group Turnover, 2016) under review, they tell us that:

a) there was a strong growth from the mid-1920's to the beginning of World War II (from a few months to almost 12 years),

b) a collapse of up to about four years during wartime,

c) a subsequent recovery from the end of the war and until the mid-1960's (with oscillating average of around six and a half years),

d) a subsequent decline from the mid-1960's until 2008-2009 (period of peak intensity of the economic crisis), with a minimum point of less than 1 year and a subsequent recovery in recent years, but without touching two years.

According to Cullen Roche (2015), this does not seem attributable to a decline in the stock return on investment, but to a higher tax burden and commissions. But it seems intuitive that other causes have had great weight and in particular, in my opinion, greater investor sensitivity to market turbulence factors, wars in particular, but also all political and economic events with global impact or very drawn out. Since the mid-1960's all the opportunities and risks related to the acceleration of technological innovation have made themselves felt, increasing both expectations and fears among investors. And therefore an ideal historical period for speculators but not for ordinary investors, especially when small. Some of these do not want to delegate the investment of their capital to institutional investors but want to handle it independently. However, the know-how of these investors (Rashes, 2001) is generally too limited to interpret complex situations arising from changes in the macro-economic and financial scenarios and their repercussions on the specific situations of the various productive sectors and individual companies. In such a situation they cannot quantify a risk since for them it has degenerated into uncertainty (Knight, 1921). This uncertainty arising from an external source combines with uncertainties that are present in the company and are mainly due to the informational asymmetries that penalize these shareholders as opposed to the majority shareholders. A way out of this situation, except of course for the sale of shares and the total abandonment of this type of investment, has been identified, as usually happens in these cases, in a distinct shortening of the time horizon of investment. Thus the advantage of choosing one company over another is based on a comparison of their results as documented in quarterly reports. This stimulates strong competition among companies over short-term results to avoid penalties in stock prices that would involve increased risks of takeover and greater fund-raising expenses. To achieve the aim of countering excessive migration of minority shareholders (the majority ones are of course firmly tied to the company), both inexpert small shareholders and also institutional investors, even projects that are advantageous for the purpose of durable creation of value for the company may be rejected (Graham et al., 2005) if their returns are deferred and therefore useless for supporting short-term results. As Shefrin (2007) observes, given that the market reacts negatively when an enterprise does not maintain its standard of short-term gains, more than half of the managers are willing to sacrifice long-term investments even if useful for developing the enterprise, if they involve sacrifices, albeit temporary, of this standard. Such "earning guidance" behavior (Cervellati et al., 2007) is in direct conflict with a company's long-term interests, which, in a context of increased competition, require investments (as for R\&D expenses) often characterized by deferred and more uncertain returns. Only for certain industries and for certain very high obsolescence lines of production it is sometimes possible and advantageous for a company to focus on investments with a very short pay-back period. In most cases investments for long-term development have deferred returns. Thus only companies that have a portfolio of such investments sufficiently large to allow for a varied combination of delayed returns can get a payment from these returns sufficient to maintain the current earnings standard. Not other companies, for whom a massive investment with deferred returns can be appreciated only by shareholders who retain long-term ownership of their shares, as in the case of majority shareholders, but not unstable shareholders, who represent a very large quota of total minority shareholding. For 
these there would in fact be no benefits, unless the market is not efficient enough to immediately and accurately anticipate in the courses the likely positive effects those long-term investments will have for the company. But such immediacy and precision are certainly rare in a real context. Thus the execution of long-term investments without a concomitant decline in the market price from an exit increase requires a reorientation of the time preferences of those shareholders, with a lengthening of their time horizon, based on the essential concept that a company itself is a long-term project. Ultimately, every shareholder should share this general plan and accept that individual projects are consistent with it. But how can small shareholders be persuaded to overcome their shortsightedness?

Scholars and operators have for some time sought to cope with this problem by linking the possible solutions to robust theoretical systems to the broader issue of governance of social organizations, including commercial companies. This link is evident in Hirschman's theory of 1970, aimed at demonstrating the usefulness of involving minority members in a more active sharing of the missions of these organizations, and which it gave rise to a series of studies and interpretations (Hirschman, 1993; Allen, 2014; Fox, 2012). Obviously the call for a greater activism is addressed to shareholders who are silent at or absent from annual meetings, and certainly not to the already active minority shareholders, and especially institutional investors, who need no stimulus to become active (Wallace, 2012). The problem is to make clear that it is in the general interest of the company and therefore in the particular interest of every shareholder to abstain from maximizing their short-term returns in favor of a more than proportional maintainment and increase of medium or long term returns. This problem is not easy to solve, in companies with both widespread and concentrated ownership. Moreover, especially in public companies, even agents/managers, who formerly were inclined to strengthen their position by sponsoring a sustainable development of enterprises, are now more inclined to allow deviations from the physiological criteria of business management, since they have obtained incentives that are proportionate to short-term company performance. Which is why this practice should be inverted in order to stop this dangerous convergence of shortsighted interests of managers and the market.

However, the increased sensitivity to short-term returns is not exclusive to public companies. Even in companies with concentrated ownership the agent (in this case the majority shareholders) hold in high regard the demands for documented short-term returns as a condition for obtaining quarterly consensus, especially if its control over the company is not particularly strong. Of course, all these problems would not exist if the market were perfect in evaluating prospective earnings, whatever their timing, as Modigliani-Miller have established as the basic condition of their famous propositions. Capital gains and sacrifices on dividends would find perfect compensation. But in imperfect real markets, and the more so the further they are from this condition, investors cannot understand the reason for low dividends for any given time. They are unsure about both the incorporation in the prices of the future benefits of long-term investments and the equitable distribution of possibly creating value in proportion to a capital share of each shareholder, given the widespread practice by the group in command of extracting private benefits.

To reduce this problem (its complete elimination would be utopian), in line with Hirschman's thought, an appropriate way seems to be to give shareholders who are in principal position the opportunity to obtain compensation for a longer stay in the company, so that they become "naturally" more likely to consider the company's long-term interest, thus overcoming their current short-sightedness. In this regard two main guidelines have been identified in the literature and in practice. The first is to give the silent shareholders the means to participate more actively and with their own "voice" in the company, and especially in meetings where the effectiveness of the management and guidelines of overall company governance are discussed and evaluated. In this way these shareholders will be able to reduce some of the informational asymmetries that by themselves add further uncertainty to the already significant and irreducible ones of the general scenario. The second is of an economic nature and therefore rests on the assumption that there is a certain component of the ownership minority which is willing to endure temporary sacrifices on dividends in exchange not for generic deferred benefits but for precise multiplicative mechanisms of them, even if adventitious.

As to both of these possible ways out of the trap of a systematic and oppressive short-termism operators and scholars have devised a number of technical solutions for making it advantageous for shareholders to lengthen their share-holding period.

\section{Empirical Tools to Counter Short-Termism with Incentives Aimed at Extending the Share-Holding Period}

Both of the above considered guidelines are theoretically designed to create, albeit in different ways and with a different emphasis, a new spirit of participation in the life and governance of a company by minority 
shareholders, very different not only from that of speculators but also from that of an occasional investor and even from the typical silent and yet stable enough shareholder of today.

The practical realization of this idealistic vision, certainly close to Hirschman's thought, is by way, with the exception of the figure of the speculator, by nature averse to remaining long in any company, of lengthening the ownership period of the shares, as the most natural way for the shareholders to develop a genuine interest in long-period returns. In turn, the lengthening of this period comes about by reducing uncertainty in the company's outer and inner environment, and since no company, however large, can by itself reduce its systemic risk scenario, the question comes down to identifying ways to reduce at least the internal obstacles to the company. The main obstacles, linked among them, are:

a) informational asymmetries that penalize the principal;

b) differences between the return for the agent and for the principal, since the former can appropriate various private benefits and gets a premium for the control if he sells his package.

The tools for achieving a partial reduction of these internal elements have been identified by operators and scholars as loyalty bonuses that can be configured in various ways, depending on the purpose one wishes to pursue, namely reducing the obstacle of point a) or point $b$ ). But it is also possible that with the same instrument one wishes to pursue entirely different aims.

As for point a), whereas asymmetric information is a natural consequence of the division between agent and principal, the bonus is structured in such a way as to give the minority shareholder a stronger "voice" in participating in both ordinary and extraordinary company assemblies. These assemblies are in fact the typical place where small shareholders can express their agreement or dissent about the operations of management, but generally in large part they desert these assemblies because they are resigned to the idea that at the end of the day their vote would be entirely irrelevant to the decisions to be made. A not unfounded opinion, seeing that, even if their shares were on the whole more numerous than those of the command group, in any case they would have a much lesser weight than the latter in shareholder decisions, since small shareholders are generally in large part scattered and unconnected while the command group is compact and united. However, active participation at the meetings is a way of establishing embryonic connections and combinations, and for gaining information that reduces informational asymmetries.

A bonus that allows an effective voice even for minority shareholders can be a wakeup call that can actually incentivize such active participation. Of course, the greater the reduction of asymmetries that follow, the smaller the pressures for short-term results will become. But even the extraction of private benefits by the agent will become smaller, as will his discretionary power over the company. And since it is the agent who effectively orients the decisions about the bonus, this will obviously be structured for the purpose of promoting the loyalty of minority shareholders to the extent of avoiding substantial damage to the agent. Thus this instrument has clear limits for involving minority shareholders in any real participation in company decisions, as in Hirschman's thought. Its only usefulness is to reduce the exit of minority shareholders who are psychologically more sensitive to unusual attention toward them by the company. On the other hand, a distinction between minority and majority shareholders is inherent to all democratic social organizations, including corporations. The only thing to do is to seek a trade-off between the conflicting interests of the two areas of shareholders in a shared assessment of the damage the company may suffer from both an excessive short-termism and a severe agency problem.

The second guideline of the bonus structure, the one based on an economic award, has a broader range of purposes and applications. The bonus can be of various kinds, even combined in appropriate forms. However, these bonuses too can involve an issue of inadequate alignment between the interests of majority and minority shareholders, or an inconsistency of the bonus structure in regard to targets.

\section{The Most Significant Types of Loyalty Bonus: Solutions to the Problem of Short-Termism or Causes of New and Bigger Problems?}

So far, of the different types of bonuses that have been developed, only one has become widespread but concentrated mainly in one country, France, at least until 2014, when it began to spread to Italy as well, following an amendment to its Corporate Governance Code. This type of bonus, which we shall call for short the "French bonus," is meant to achieve only the above-mentioned objective a), since it focuses only on a predetermined increase in voting rights. The voting increase is given to a share that has been continuously held by the same shareholder for a predetermined period, on condition that in case of a subsequent sale of the share the bonus immediately expires, by which the share reverts to a single vote. The vote increase can vary in size, from a fraction to a multiple of the previous single vote per share (Dallas, 2011), without subsequent increases 
over time. This type of bonus has aroused great interest and lively debate in France and Italy, while it has been rather neglected elsewhere, especially in countries with an Anglo-Saxon financial culture, typically tied to the "one share, one vote" principle (Moore \& Gillyon, 2015), which is clearly overturned when the vote is enhanced (Adams \& Ferreira, 2008; Linciano, 2014; Burkart \& Lee, 2008; De Beaufor, 2006; Ferrarini, 2006; Hayden \& Bodie, 2008; Khachaturyan, 2006; Wong, 2013). It is true that if the loyalty share is sold its loyalty ceases and with it the vote increase, and this prevents from the outset the creation of two distinct markets, one for loyalty shares and the other for non-loyalty shares, with two different prices. But in the meantime, for the indefinite period in which it remains loyal, which can last as long as the company exists, the loyalty share gives increased power within the company, and so modifies the power relationships among the shareholders. Thus in more recent years there were lively expectations of a new type of bonus that could lengthen the share holding period without causing alterations of that general principle.

A composite type of bonus was presented in 2012 by Bolton and Samama in a conference at Columbia University, where they attracted significant attention and a broad consensus. In the model, the bonus is represented by a call option which is linked to the share as a warrant and gives the shareholder, once he has owned the share for the specified period, the right to underwrite or acquire additional shares of the same company in a pre-established relationship with his loyalty shares at a predetermined price and also within a fixed period. The economic profile is dominant in this bonus. But the voting implications are also obvious, since they are related to the increment in the number of shares. However, these remain each with a single vote so that the "one share, one vote" principle continues to be respected. Obviously, however, the actual increase of the votes in the hands of the loyal shareholders is not a safe event since it is subject to the fact that the market price is higher than the Strike Price in the time window within which the bonus can be exercised. Thus this bonus has a randomness profile that is absent from the French model, where the bonus is safe at the maturation of the loyalty period. However, the French bonus is in turn random in its duration, since this is lost if the share is sold, while in Bolton's and Samama's model it is not revoked when, after the option has been exercised, the shareholder decides to sell his shares. The bonus is lost only if the shareholder sells his shares when the loyalty period has not yet expired.

Quite clearly, the two different bonus structures impact differently and to varying degrees on realizing the aim of reducing exit or even other aims, which, although not made explicit, may underlie the granting of a bonus.

\subsection{Crucial Aspects of the French Model}

In this model the bonus not only creates discrimination between loyal and non-loyal shares, as in its declared intentions, but also generates an indirect and less obvious discrimination between the total areas of majority and minority shareholders, to the detriment of the latter (Ecchia \& Visconti, 2016). How can this heightening of existing disparities in their respective positions come about? It is sufficient to note in this regard that:

a) if at the time of granting the bonus account is also taken of past loyalty, it is obvious that the loyalty period requirement is, in percentage terms, much more in the area of the majority than in that of the minority shareholders;

b) if only the period starting from the introduction of the bonus is taken into account, the situation is more equitable, since the starting line is the same for all shareholders, but in any case the loyalty percentage will be more widespread in the area of the majority shareholders, although less so than in point a). The majority shareholders are more tied to the company for emotional reasons if they are founders or senior partners, and/or for economic reasons such as private benefits, which are additional reasons to those of the minority shareholders.

Therefore, in any case, the bonus will be premiumed, in the area of the majority of shareholders to an extent (highly probable) exactly proportional to the number of shares held by the majority shareholders, and to an almost certainly less proportional extent in the area of the minority shareholders, since a more or less considerable part of the latter, starting with speculators, will not be interested in a prolonged stay in the company.

The lower percentage of the loyalty requirement in the area of minority shareholders creates a leverage effect in terms of a percentage incidence on the new vote total in favor of the majority shareholder area. This effect is stronger:

1). the greater the increase in the vote of each loyalty share and

2). the longer the loyalty period.

This combined effect is interesting not so much where the command group already has more than $50 \%$ before the introduction of the bonus, because in this circumstance the group has less of a need to reinforce itself, but when has only a relative control, less than $50 \%$, and so must hope for the absenteeism of many small 
shareholders so that it can impose its will in shareholders' meetings. Nevertheless, it is important to note that if in order to obtain absolute control, this group pushes hard on the leverage elements described above, it could provoke in regard to the former (the extra vote) a boomerang effect if this generous extra vote is likely to induce a great mass of smaller minority shareholders to remain in the company for the entire loyalty period and beyond (since the bonus is lost when the share is sold). In this case, the above indicated leverage in favor of the command group would largely come to naught. Moreover, this situation could bring to the fore a leader capable of uniting most of the minority shareholders and transforming their minority position into a majority, thus ousting the previous command group from its position of company control.

\section{EXAMPLE}

Based on the following assumptions:

Total number of shares, each with a single vote 100

Number of shares pertaining to the command group 40

Number of shares of the other shareholders 60

Number of shares deposited on average to participate at shareholder meetings 70

Number of shares deposited by the command group 40

Number of shares deposited by the other shareholders 20, including eight close to attaining the loyalty requirement.

Number of shares of absentee minority shareholders 40 , of which 20 close to attaining the loyalty requirement.

Based on these assumptions, the command group, even if it does not have the majority of the capital, has no trouble gaining control of decisions in an ordinary shareholders' meeting thanks to a significant absenteeism that is typical of many small shareholders. In this example a command group with just $45 \%$ of the capital can outdo all other shareholders having $60 \%$.

If in the following year a 1 bonus vote comes into play for each group of four loyalty shares, and assuming that all the people in the command group have matured their loyalty period, while only 20 of the other shares satisfy this requirement, the number of votes that can be exercised by the command group rises to 50 while that of the other shareholders rises to 65 . The vote increase in the hands of the minority shareholders not only is less than proportional to that of the majority shareholders but even less in absolute terms. If we assume that all the loyal shares of the minority shareholders are deposited (with a power of 10 votes) and next to them another 10 non-loyal minority shares, the total number of votes of the minority shareholders participating in the meeting rises to 22. Therefore, the gap with the command group has increased. However, things can change a lot if a larger extra vote, for example one extra vote for every loyal share, is able to transform the behavior of the small minority shareholders, the typical absentee ones, giving them a greater incentive to attend the meeting. This can happen especially if, under the stimulus of such a vote gratification, there comes forth from among them a leader capable of seeing the potential of a group action of these shareholders thanks to the bonus. In this case the votes in the hands of the command group rise to 80 , the loyal shares, which have become 28 , have 56 votes to which we must add another 32 votes in the hands of non-loyal shareholders, for a total of 88 votes. Potentially, if at least 31 of the non-loyal shares of the minority shareholders are filed, the command group loses control. In short, the "extra" voting system is a mechanism that the command group should dose out with great care to avoid losing control because of psychological changes in the behavior of the small minority shareholders. If the bonus is very low it actually serves the command group as CEM, while beyond certain limits it becomes a boomerang for the command group if its previous control was precarious (under $50,1 \%$ of the capital) and the hope of a turnover of command rouses the interest of a large number of small shareholders to participate in meetings.

The bonus entity thus contains a counterweight mechanism that can mitigate, though certainly not cancel out, the role that this bonus can have as a CEM for a command group with weak control. Ultimately, this bonus can attribute to the majority shareholders an extra number of votes proportionally greater than that attributed to the minority shareholders, but it is not a CEM in an absolute sense. In itself it reinforces the votes of the majority shareholders only in proportion to their loyal shares. It is instead the almost certain deficit of loyalty in the area of the minority shareholders that determines the corresponding more than proportional reinforcement of the majority shareholders in terms of percentage incidence on the new total of votes and therefore the transformation of the original function of the bonus into that of a CEM. If this deficit does not manifest itself, the balance of power remains unchanged. Instead, no counterweight mechanism exists for the second factor of leverage, i.e., the duration of the loyalty period. The greater this duration the more a minority shareholder may be discouraged 
from remaining in the company. Therefore, the command group can combine a long duration of the loyalty period with an extra large vote to reinforce itself, at the same time counteracting the risk from an excessive extra vote.

However, the transformation of the bonus into a CEM is predictable from the start, as are also the real intentions of the majority shareholders when approving the introduction of the bonus. If the small shareholders do not understand this stratagem (institutional investors understand it perfectly and in fact oppose this bonus), it is clear that the bonus is used as a ruse for the small shareholders. It is therefore with the intention to restrict this discretionary space of the command group that the French legislature has recently imposed as a default rule that:

a) the bonus should kick off automatically after two years of uninterrupted possession and

b) it should take the form of an automatic doubling of the vote.

While it is true that this is just a default rule, command groups with weak control are forced to vote differently on these matters if they want to avoid the risk of losing control of the company. And a resolution of this kind can arouse the suspicions of the small shareholder gulls, which may fly elsewhere.

But there is no denying that this kind of bonus could also have (the conditional is a must in this case) positive effects at least as regards long-termism. The bonus, even in its role as CEM, represents in any case a chance for the company to get out of being backed into the corner of short termism. If this chance is used to make a better selection of projects this is a positive development for the company as opposed to the previous short-termism, with benefits for all shareholders. If the leadership of the command group is appreciated by the market, it will be appreciated yet more for its reinforcement, and so there will be no minority shareholder drain and those who want in any case to opt for exit meet an influx of new investors without price sacrifice. But in cases where the judgment on the command group is not very favorable, the market price should register the introduction of the bonus negatively. The French experience highlights the application of this bonus by about two-thirds of the companies listed and there is no clear evidence that the market penalizes the value of these companies (Belot, 2005; Chene, 2008). Quite the contrary, perhaps thanks to the contribution that the mandatory quotation (which takes precedence over companies that want this bonus) gives to market enlargement and to share liquidity (Ginglinger \& Hamon, 2007), although institutional investors take a different attitude.

Doubtless many factors complicate a correct market assessment, and it is clear that to the extent that the market is far from conditions of full efficiency, some aspects may be overestimated and others underestimated. It would be especially dangerous to underestimate the possible "immobilization" of control in the hands of the command group, as a result of its marked reinforcement. Although at the moment this group is efficient, in time the validity of the company leadership could be seriously compromised, as shown by the experience of unfortunate generational changes. In addition, the market price is applicable only to "floating", so the packets of minority shareholders, while other (neglected) complications arise with the introduction of a bonus even for an over-the-counter price for the control unit packet. This is generally higher than the market price thanks to the control premium, which is a good proxy of the extraction of private benefits from that group. In the presence of the French bonus, the premium evaluation for control must take into account that the shares that are traded automatically lose their extra vote, so that the new votes of this packet have a lesser impact on the new totality of votes. The buyer receives shares with a single vote, while, in the area of minority shareholders, the portion of loyal shares continues to benefit from the extra vote. The price penalization of this packet is therefore certain. Therefore, if on the one hand this bonus, acting as a CEM, protects the enterprise from any strong market control, which instead takes place in diffused property companies, on the other hand the command group becomes a "prisoner" of this mechanism which it has desired itself. To rid itself of it, it must submit to a much lower price, compared to what it would be able to obtain in the absence of bonus, the higher the extra vote. It can only negotiate a slightly higher price than the stock exchange price and only thanks to the fact that the buyer who wants a big share packet is willing to pay a little more to avoid splitting the purchase over a long period (excessively concentrated purchases would cause large price increases). But in any case this over-the-counter price does not include a control premium or not of an amount comparable to the one preceding the bonus introduction. In short, the effects deriving from the escape from captivity are unavoidable and onerous for all shareholders, majority or minority ones, loyal or not loyal.

\subsection{Crucial Aspects of the Bolton and Samama Model}

Unlike the French system, where the bonus is free of charge, Bolton and Samama's, by focusing on a call option, should normally imply the payment of a premium to get the call, unless one wants to consider that in any case a price for the bonus is implicit in the waiver by shareholders of other investment opportunities during the loyalty period. Since it is a call option, the bonus can be linked as a warrant to the share from its issuance, or assigned 
separately at a later time, in concomitance with special company circumstances. The effective exercise of the bonus naturally implies, unlike the French model, another cost, inherent to the payment of the Strike Price, which, however, unlike the call premium, is merely possible, not certain, since it will be supported only if the market price of the share exceeds the Strike Price in the period in which the call can be exercised. Again, unlike the French model, here the operation of shareholder adhesion to the bonus offer can also lead to a negative result: a loss of capital if the difference between the share market price and the Strike Price is less than the cost of the call premium.

Can this bonus configuration as a call option help to reduce exit and support the share's market price? At first glance the logic should be developed according to that of the options theory. The bonus/call option adds itself to the normal call represented by the share as quota of the company's capital (Black \& Scholes, 1973). Since the bonus/call has as underlying element the equity/call, and this, in turn, has as underlying element the company's investment portfolio, given that option value is greater in direct proportion to the volatility of the underlying activity, it follows that a leverage effect is created on the value of the shares, compared to a situation without bonus, the greater in direct proportion to the volatility of the business investments. Therefore the bonus makes the most innovative and so riskier investment more advantageous (despite of their dislike of deferred returns), of course within the limits in which the cost of debt is slow to react and with it the whole WACC (weighted average cost of capital) chain, with a consequent impact on the new readjustment, this time downward, of the market price. Within these limits, shareholders may be motivated to hold onto their shares until the loyalty period is over. In practice, the company bets on a low credit market efficiency.

Of course, it is clear that, in addition to these economic aspects of the bonus, those related to possible changes in governance must also be evaluated. The redistribution of the new total equity shares should entail a redistribution of shares of the new vote total. In this regard, the effects on governance seem similar to those examined in the French bonus: a greater concentration of votes among the majority shareholders due to the greater presence in this area of the loyalty requirement, with a leverage effect on vote power directly proportional to:

a) the number of new shares allocated from the bonus compared to the number of loyal shares,

b) the length of the loyalty period.

Thus in this bonus model too the command group would seem to obtain, if exercising the call, a reinforced control as in the French model, and this fact would equate them to CEMs (if, as is normal, the new shares purchasable thanks to the bonus also have voting rights).

However, as in the French model, the leverage effect of the bonus has an intrinsic counterweight in relation to point a). The command group should consider that a very high "new shares/ loyal shares" relationship could provide an incentive for a broader section than desired of the minority shareholders to hold onto their shares until the end of the loyalty period and perhaps to come to some mutual understanding. In this case, the leverage would be very reduced, and the minority shareholders could gain not only a stronger "voice" but even the control of the company if the previous control by the command group was precarious.

But this type of bonus has other limits that are not present in the French bonus.

One of these limitations is its limited duration as a loyalty factor. In fact, once the call is exercised, the shares thus purchased may be sold immediately without loss of the bonus. Therefore, the loyalty is high only during the holding period and mainly, or only, because the shareholder has paid from the beginning a monetary premium for the call option. In fact, this premium raises a barrier, the higher in direct proportion to the premium, against exit.

But only up to the moment when the call is exercised, not also later as in the French bonus, where the loss of the bonus with the sale of the share exerts a permanent incentive to hold onto it. Further, in Bolton and Samama's bonus, not even the command group suffers the captivity effect, unlike the French bonus.

Ultimately, the fact that the bonus is not revocable once the call is exercised it triggers the termination of the incentive to extend the share-holding period. It is a fixed-term incentive, and inconsistent with a company's long-term strategy. Hirschman's ideas are very distant from this model.

But a very different criticism can be made, in my opinion, of Bolton and Samama's bonus. It is the logic underlying the structure of this bonus that, in itself, presents severe limitations as to the effectiveness of the mechanism on which it is based and of the loyalty action at which it is aimed. In fact, it suffices to recall that:

A) as a result of exercising the option, the market price (the same for all shares) falls toward a new equilibrium between the previous market price and the Strike Price, with a lowering that is a direct function of both the difference between these two prices and the number of new shares with respect to the new total number of 
shares.

B) for loyal shareholders who have exercised the option this lowering of the market price is usually more than proportionally offset by the gain that comes from the call to the Strike Price (except where the difference in that moment between the market price and the Strike Price is so small that it does not even allow a complete recovery of the call premium).

C) for the other shareholders, however, there is no compensation.

Therefore, the option mechanism reserved for loyal shareholders acts, all other conditions being equal, as an incentive towards the exit solution for non-loyal shareholders. Therefore it acts as a brake on the chances of the market price exceeding the Strike Price, with a force proportional to the magnitude of the factors of point A). Moreover, these depressive effects can give rise to some uncertainty, even in loyal shareholders, about the actual advantageousness of paying a call premium in view of the fact that the chances of the market price exceeding the Strike Price plus this premium are small compared to a situation where there is no discrimination among shareholders on the basis of the loyalty requirement. Ultimately, this mechanism, in the presence of such a discrimination, has boomerang effects that can only be avoided by suppressing the call premium and extending the option to all shareholders, regardless of the seniority of their shares. In this case, however, there would not be a clear need for a call option that would not generate any differential effect on the individual quotas of social capital in the hands of each shareholder but would simply allow a possible capital increase for the company. This would not necessarily be a benefit since it would occur in a deferred period with respect to the current needs of the enterprise. If the enterprise were to immediately realize massive investments, an ordinary and immediate capital increase with the issuing of new shares would certainly be more appropriate. If the Board does not believe that the new shares can be easily placed and resorts to a bonus/call the reason is that it obviously confides in a lack of shareholder rationality.

\subsection{Crucial Aspects of Other Possible Types of Bonuses}

Other types of loyalty bonuses have been suggested or can be easily conceived, but it is difficult to find any that can reconcile two points of view as different as that of the majority and minority shareholders in a shared vision of a common basis of interests. A type of bonus that was taken into consideration in a report to the European Commission of Inquiry on multiple voting shares, and as an alternative to this (European Commission, 2007; ECGS, 2014) focused on a dividend increase on shares that the loyalty period had matured, on condition that the bonus should terminate if the share were sold. A bonus of this kind, having no influence on the vote, would avoid the problems generated by a CEM, but would have negative effects on the share's market price because new potential investors would take account of the fact that they would be purchasing non-loyal shares and so would be penalized in terms of dividend distribution until the maturation of the loyalty period, because in the meantime the loyalty shares would have a right of first refusal, on the overall dividends, more than proportional to their nominal value.

Obviously a variety of other bonuses can be conceived, and many with a variety of extra vote and extra dividend combinations. But so far no scholar or operator seems to have worked out the magic formula for extending the holding period and promoting long-termism without creating other, sometimes larger problems.

\section{Conclusions}

What conclusions can be drawn from this analysis?

Certainly the recourse to instruments such as bonuses to cope with the pressures of small investors and some institutional investors for short-term returns is justified by the need to escape the impasse of a short-termism in selecting projects that are practically imposed by a market where the consent of the company is based on the results of periodic infra-annual reports. This submission to market preferences, definitely dangerous for the sustainable development of the enterprise, is logically stronger when the company is listed and control by the command group is precarious, so that straying from market expectations would imply exposure to risks of takeover and more onerous fund raising. If each company paid no heed to these pressures of minority shareholders, the passing from one company to another by disgruntled investors would tend to balance out in the end, but each company is in the dark about the decisions of the others and so the competition in the short run generates a leveling downward of the selection quality of projects. This contrast between financial market pressures and the logic of a company's sustainable development is of great importance not only for individual enterprises but also for national economies. Of course, this can attract the attention of legislators at the national level and induce them to find ways to enable enterprises to maintain or regain a long-term vision. Therefore, loyalty bonuses, which were initially developed and tested in a strictly private vision and in a context of private 
interests, are now also considered possible instruments for a "soft" State intervention to facilitate better national development. In a less benevolent interpretation (Zingalez, 2014) the State has used them to maintain control of the enterprises in the public sector while attracting private capital, so as not to burden the public purse. Probably both purposes coexist. But this is not an interesting point for the purposes of this work. Our focus is only on the issue of the usefulness of a bonus for increasing long-termism without generating excessive collateral problems. On the basis of our analysis, the French type bonus is the only one that induces shareholders to stay put indefinitely, since the bonus is lost if the share is sold. But it is also the bonus that multiplies the risk of an immobilized control, and not only because the command group is thus reinforced but also because it remains in a situation of "captivity." Nonetheless, with all its advantages and disadvantages, this is the only type of bonus that can resist, at least in part, any criticisms that may be lodged against it. The other bonuses do not create, it is true, immobilization but, in my opinion, their structure is not consistent with the purpose of shareholder loyalty. This is also the case with Bolton and Samama's model. But if the French model seems the only one with some, albeit limited, rationale, it seems strange that it has not yet become popular outside of France and Italy. In particular, it is ignored in the Anglo-Saxon countries, which are usually more open to innovation. However, two possible explanations can be advanced. The first is the role of CEM, for the command group, which in effect underwrites the bonus and, paradoxically, in inverse proportion to the loyalty of minority shareholders, which should be the real purpose of this bonus. This deviated role can be appreciated in countries where company ownership is usually concentrated but in many cases not enough to ensure the command group the absolute control it seeks. In Europe, where public companies are rare, command concentrated in a few hands is the norm (Facci \& Lang, 2002). An instrument that can reinforce the command group more than proportionally to the invested capital is seen as a not very serious infringement on company democracy if it enables the command group to be free to make decisions in the long-term interests of the enterprise. Market discipline, however, penalizes all the shareholders who abandon the company, whether they are minority or majority, loyal or not loyal, because the buyer purchases one vote shares and enters a company in which part of the other shareholders have increased vote shares, so that he will demand a discount compared to the situation of a company in which all the shares are just of the one vote kind. This penalization could find some justification when the "punishment" is meted out to those who abandon the ship not because it is sinking, but simply because it does not follow the course of their short-sighted interests. But this is not always so. And in any case the breach of an ideal of company democracy is quite clear. To counter the short-termism of a not very efficient market, an instrument is adopted that reduces the democratic functioning of the market itself. Without expressing an ethical type opinion, we may observe that, if it is the lack of market efficiency that induces the control unit to reinforce itself in order to pursue the interests of the enterprise, then the bonus is entirely useless and even harmful if the company is listed in an efficient market. In such a market, the assessment of an enterprise and the selection of its projects is aseptic, whatever the timing of its returns, and aimed only at ascertaining their effects on long-term value creation for the company. The market price does not reward those who buy and those who sell; it is neutral. So the problem is only one: market efficiency. Is there any fully efficient market?

On the basis of the phenomena we have previously analyzed, it is tempting to give a negative answer. The great lowering of the holding has aroused great concern. Nonetheless the importance of the phenomenon must be placed in proper perspective, since it is probably due for the most part (although there is no precise evidence in this respect and we can only reason intuitively) to the explosion of speculation, by professional and institutional operators and by a growing mass of small "do-it-yourself" speculators. Therefore the current extremely short holding period signifies only a much greater turnover of part of the capital that, all other conditions being equal, is not much greater than that of the years before the speculation progressively took place. If so, the current anxieties about short-term company results certainly appear exaggerated. To the extent that this hypothesis is founded, the quarterly reports can simply play the role of offering a periodic check on the efficiency of the management, but if there are well-founded reasons for temporary deviations of current returns from standards and benchmarks, these are correctly considered and shareholders who want to sell find a quid pro quo without price sacrifice. But all this in a very efficient market. No market is of the perfect Modigliani\&Miller kind, which realizes the expected returns immediately and with absolute precision in their prices, whether they are little or greatly deferred. Therefore, although to date the Anglo-Saxon markets have turned up their noses to the French loyalty bonus, it cannot be excluded that in the future this severe behavior will change. In fact, unfortunately, almost everywhere in the world the trend seems to be towards a greater decision-making power at the heads of social organizations, and in particular companies, as something considered essential in phases of great scenario uncertainty, even if it means giving up the more democratic "one share, one vote" principle. So that the role of the bonus may have a future, in all its negative aspects and some positive ones. 


\section{References}

Adams, R., \& Ferreira, D. (2008). One Share-One Vote: the Empirical Evidence. Review of Finance, 12, 51-91, https://doi.org/10.1093/rof/rfn003

Allen, M. M. C. (2014). Hirschman and Voice. In A. Wilkinson, \& J. Donaghey (Eds.), Droit de vote double e "voting caps": Quel impact pour les entreprises francaises? Memoire de DEA, Université Paris Dauphine, https://doi.org/10.4337/9780857939272.00010

Black, F., \& Scholes, M. (1973). The Pricing of Options and Corporate Liabilities. Journal of Political Economy, 81(3), 637-654, https://doi.org/10.1086/260062

Bolton, P., \& Samama, F. (2013). Loyalty Shares: Rewarding Long-Term Investors. Journal of Applied Corporate Finance, 25(3). https://doi.org/10.1111/jacf.12033

Burkart, M., \& Lee, S. (2008). One Share-One Vote: The Theory. Review of Finance, 12, 1-50, https://doi.org/10.1093/rof/rfm035

Cervellati, E. M., Della Bina, A. C. F., Pattitoni, P., \& Tasca, R. (2007). Earnings forecasts bias and accuracy in the Italian Stock Market. Working Paper Newfin, n. 207.

Chene, N. (2008). Memoire de recherche. Le droit de vote double en France. Panorama de son utilization et impact en termes de valorization des societies. (Sous la direction de Ulrich Hege). Retrieved from http://www.vernimmen.net

Dallas, L. (2011). Short-termism, the Financial Crisis and the Corporate Governance. Journal of Corporation Law, 37, 264.

De Beaufor, V. (2006). One share-one vote. The new Holy Graal ESSEC Centre de Recherche.

ECGS. (2014). ECGS commented on CONSOB's Consultation on Multiple Voting Rights. Retrieved from http://www.ecgs.net/node?page=7

Ecchia, B., \& Visconti, R. (2016). The extra vote as Bonus for loyalty shares in the Evolution of the French Model. What Effects does it have on Shareholder Relationships, "Longtermism" and Company Market Value? International Journal of Business and Social Science (IJBSS), 7(10), 116-132.

European Commission. (2007). Report on the Proportionality Principle in the European Union. Retrieved from http://www.ecgi.org/osov/documents/final_report_en.pdf

Faccio, M., \& Lang, L. (2002). The ultimate Ownership of Western Europeans Countries. Journal of Financial Economics, 65, 365-395. https://doi.org/10.1016/S0304-405X(02)00146-0

Ferrarini, G. (2006). One Share -One Vote: A European Rule? Institute Law and Finance, Universitat Frankfurt, Working Paper Series, No. 47, 04/2006. https://doi.org/10.1515/ecfr.2006.007

Fox, J. (2012). Exit, Voice and A.O. Hirschman. Harvard Business Review. Retrieved from https://hbr.org/2012/12/exit-voice-and-albert-o-hirsch.html

Gazzetta Ufficiale of Italian Republic. (2014). Law 116/2014, n. 302, 31st December.

Ginglinger, E., \& Hamon, J. (2007). Ownership, Control and Market Liquidity. Retrieved from http://ssrn.com/abstract=968008, https://doi.org/10.2139/ssrn.1071624

Graham, J. R., Harvey, C., \& Rajgopal, S. (2005). The Economic Implications of Corporate Financial Reporting. Journal of Accounting and Economics, 40, 3-73. https://doi.org/10.1016/j.jacceco.2005.01.002

Hayden, G. M., \& Bodie, M. T. (2008). One Share, One Vote and the false promise of Shareholder Homogeneity. Retrieved from http://www.scholarlycommons.law.hofstra.edu/faculty-scholarship

Hirschman, A. O. (1970). Exit, Voice, and Loyalty: Responses to Decline in Firms, Organisations and States. Cambridge, MA: Harvard University Press. Retrieved from http://www.hup.harvard.edu/catalog.php?isbn=9780674276604,

Hirschman, A. O. (1993). Exit, Voice and the Faith of the German Democratic Republic: An Essay in Conceptual History. World Politics, 45(2), 173-202. https://doi.org/10.2307/2950657

Khachaturyan, A. (2006). The One Share-One Vote Controversy in the EU. https://doi.org/10.2139/ssrn.2005054

Knight, F. H. (1921). Risk, Uncertainty and Profit. Boston, MA: Hart, Schaffner \& Marx; Houghton Mifflin Co.

Linciano, N. (2014). La deviazione dal principio un'azione un voto e le azioni a voto multiplo. Quaderno 
giuridico CONSOB, 5/2014

Moore, M. Q. C., \& Gillyon, P. (2015). "Loyalty Shares" and Weighted Voting Rights in Companies formed and registered under the Companies Act. Butterworth Journal of International Banking and Financial Law, 6, 334.

New York Stock Exchange. (2017). "NYSE Group turnover” 2000-2015. Accessed January 2017

Rashes, M. S. (2001). Massively Confused Investors Making Conspicuously Ignorant Choices (MCI-MCIC). Journal of Finance, 56(5). https://doi.org/10.1111/0022-1082.00394

Roche, C. (2015). How to avoid the problem of short-termism. ORCAM Financial Group. Retrieved from http://www.pragcap.com/how-to-avoid-the-problem-of-short-termism/

Shefrin, H. (2001). Behavioral Corporate Finance. Journal of Applied Corporate Finance, 14(3), 113-126, https://doi.org/10.1111/j.1745-6622.2001.tb00443.x

Shefrin, H. (2007). Finanza aziendale comportamentale. Decisioni per creare valore. Apogeo, Milano.

Wallace, C. (2012). Can Loyalty Shares Programs Help Build Long Term Value for Investors? Institutional Investors, October 18, 2012.

Wong, S. C.Y. (2013). Rethinking “One Share-One Vote”. Harvard Business Review, January 29, 2013.

Zingalez, L. (2014). Quel voto plurimo così opaco. Il Sole24Ore, 1st August 2014.

\section{Copyrights}

Copyright for this article is retained by the author(s), with first publication rights granted to the journal.

This is an open-access article distributed under the terms and conditions of the Creative Commons Attribution license (http://creativecommons.org/licenses/by/4.0/). 